persisted in the industry, while the known relationship between silica and tuberculosis had faded from memory. The arrival of HIV, another cofactor for tuberculosis, in the $1980 \mathrm{~s}$ found a large population of men living in single sex accommodation far from their families.

Understanding of this co-epidemic was also limited by the migrant labour system, which had resulted in two subpopulations numbering in the millions in dynamic association with each other. The first were those employed and thus under radiological, clinical and post-mortem surveillance for lung disease, and subject to health selection into and out of the industry. The other were ex-miners, dispersed through remote rural areas with poorly developed economies and health services, to which the burden of mining related lung disease was shifted and whose health experience remained hidden. The Southern African experience of silicosis and tuberculosis and related disorders holds lessons for other countries with active and growing extractive industries. More generally it should also direct our attention to areas of the world dependent on large number of migrant workers employed under harsh conditions, whose work related ill health is 'externalised' in various ways. Occupational health needs to regain its public health perspective.

\section{THE IMPORTANCE OF WORKERS' HEALTH TO ADVANCE THE UNITED NATIONS SUSTAINABLE DEVELOPMENT AGENDA}

Gerry Eijkemans. Head of Country Office, Pan American Health Organisation/World Health Organisation, Mexico

\subsection{6/oemed-2018-ICOHabstracts.4}

Introduction The 2030 Agenda embraces the three dimensions of sustainability - economic, social and environmental. It was adopted by world leaders at the United Nations in September 2015. The 2030 Agenda for sustainable development puts people and planet at its centre and gives the international community the impetus it needs to work together to tackle the formidable challenges confronting humanity, including those in the world of work and for improved health for all.

Discussion WHO has recognised that addressing social determinants of health - the conditions in which people are born, grow, work, live, and age, and the wider set of forces and systems shaping the conditions of daily life- are key for the creation of health; employment conditions are essential in this context.

When examining the situation and role of workers' health in the SDGs, we see that over the last years limited progress has been made; The latest ILO figures show that work-related fatal injuries and diseases have increased from 2.3 million to 2.78 million per year, increasing the global cost of the failure to adequately address occupational safety and health concerns to an estimated 3.94\% of global GDP per year, or 2.99 trillion US dollars. Roughly half the world's population still lives on the equivalent of about US\$2 a day, and in many places, having a job does not guarantee the ability to escape from poverty. This slow and uneven progress requires us to rethink and retool our economic and social policies aimed at eradicating poverty.

The 2030 agenda seeks to reduce poverty and to increasing equity. Some specific SDG objectives are achieving Universal Health Coverage (still only $15 \%$ of workers worldwide have access to specialised occupational health services) and achieving full and productive employment and decent work for all women and men.

These are very ambitious goals; but they are essential and they are feasible. But in order to meet those goals, the world needs to focus on people, by implementing public policies that improve employment conditions and health of workers, through a very close coordination among government agencies responsible for health, labour, social security and economic development, together with employers and workers' organisations.

\section{CONNECTED WORKPLACE HEALTH, SAFETY AND WELLBEING IN AN IRISH CONTEXT}

John Gallagher. University College Hospital and University College, Cork

\subsection{6/oemed-2018-ICOHabstracts.5}

Irelands industrial heritage is often overlooked. Though not of the same scale as our closest neighbour Ireland has a significant industrial past. The famine not only led to depopulation particularly of rural areas but also to urban drift and the growth of factory labour. Early health and safety legislation focused on extractive, manufacturing and transport industries. Modern Irish legislation has encompassed the terms health, safety and welfare from its inception in 1989. The practical focus has been on the safety component, a reflection of preceding legislation. Over the last 10 years there has been an increased focus on health and welfare and a move toward the concept of wellness. The concept of Total Worker Health though more established overseas and particularly in the United States, is a new arrival in Ireland. This approach attempts to integrate the functions of occupational health, health promotion, and health protection programs with the aim of improving employee health, minimising work-related injuries and illnesses, and reducing employee health care-related costs. It has been embraced to varying degrees by different organisations and with varying levels of success. Prof Gallagher will discuss the reasons behind this and will look at some recent evidence and case examples in Ireland. He will address where occupational medicine fits into the concept of total worker health and how this may develop in the future. This has implications for the discipline of occupational medicine which he will also address. Finally he will look at the challenges and opportunities of connected health approaches.

\section{PSYCHOSOCIAL CONDITIONS AFTER OCCUPATIONAL INJURY}

1,2,3 Leon Guo, ${ }^{4}$ Judith Shiao, 1,2,3 Weishan Chin. ${ }^{1}$ Environmental and Occupational Medicine, National Taiwan University College of Medicine and Hospital; ${ }^{2}$ National Institute of Environmental Health Science, National Health Research Institutes, Taiwan; ${ }^{3}$ Occupational Medicine and Industrial Hygiene, National Taiwan University College of Public Health; ${ }^{4}$ School of Nursing, National Taiwan University College of Medicine, Taipei, Taiwan

\subsection{6/oemed-2018-ICOHabstracts.6}

Introduction Annually in the world, more than 300 million nonfatal occupational accidents occur requiring at least 4 days of absence from work. Elevated psychiatric disorders and psychological symptoms are reported after occupational injuries. In addition, those with poorer psychological conditions had lower probability of returning to work, and those who with a disability of the upper or lower extremity tended to have higher mortality from selfharm in later life than did the general population. In cases of severe injury, a proportion of workers spent the rest of their life suffering from psychological ailments.

Methods Using the available information on incidence rates of occupational injuries, and related psychological and psychiatric ailments after occupational injuries, overall psychosocial 
impacts as a result of occupational injuries are estimated, including psychiatric diseases, psychological symptoms, disability from work, and suicides.

Result Psychiatric diseases worldwide are caused directly or indirectly by occupational injuries. The less severe forms of mental consequences are psychological symptoms or preclinical psychiatric conditions. Significant percentage of permanent disabilities are caused by psychiatric conditions related to injuries. In addition, delayed return-to-work, i.e., longer duration of temporary disability is found among injured workers with psychological symptoms. A special form of psychological/psychiatric condition, suicides and suicidal ideation are increased among injured workers. There are still limitations in this analysis due to a great varieties of psychological outcomes obtained, and to lacking of epidemiological assessment of these conditions after occupational injuries.

Discussion Generally, the psychosocial impacts of occupational injuries are greater than generally understood. In addition to preventing occupational injuries, secondary and tertiary prevention to minimise psychosocial impacts are warranted.

\section{5 'VISION ZERO' - FOR A WORLD OF WORK WITHOUT FATAL AND SERIOUS ACCIDENTS}

Hans-Horst Konkolewsky. International Social Security Association (ISSA) based in Geneva, Switzerland

\subsection{6/oemed-2018-ICOHabstracts.7}

There is a growing international consensus that efforts to develop a global prevention culture should be reinforced in order to reduce the unacceptably high number of work accidents and occupational diseases worldwide. It is at the same time recognised that business performance is highly depending on a healthy and motivated workforce.

The ISSA has on this background developed a new prevention concept, called 'Vision Zero', which is based on the belief that all accidents and diseases at work can be prevented. The ISSA's Vision Zero approach is flexible and can be adjusted to any workplace, company or industry.

A global Vision Zero campaign was launched at the XXI World Congress for Safety and Health at Work in September 2017 in Singapore, which aims to mobilise business leaders to integrate safety, health and well-being at work in their core management function as well as company culture.

To this end the ISSA has developed a Vision Zero Guide that outlines a roadmap with 7 Golden Rules to help improve a company's safety and health performance as well as practical checklists and training materials.

More than 700 Companies and OSH-organisations from more than 90 countries have since its launch joined the campaign as Vision Zero Companies or Partners.

\section{GENE-ENVIRONMENT INTERACTION: PROMISES AND PITFALLS OF MOLECULAR EPIDEMIOLOGY AND TOXICOLOGY IN OCCUPATIONAL HEALTH}

A Mutti ${ }^{*}$. University of Parma, Parma, Italy

10.1136/oemed-2018-ICOHabstracts.8

Most Gene x Environment $(\mathrm{G} \times \mathrm{E})$ studies focused on polymorphic variants in metabolism genes affecting metabolic function of proteins that activate or detoxify exogenous and endogenous toxins. Examples include members of the cytochrome P-450 (CYP) superfamily of proteins, N-acetyltransferase 2 (NAT2), and glutathione S-transferases (GSTs) that are implicated in cancer, Parkinson disease (PD), and Alzheimer disease. For example, long before the first familial PD gene was identified, the 'poor metabolizer' enzymatic phenotype of the cytochrome P450 2D6 (CYP2D6) gene was the first PD candidate gene because the enzyme is active in the brain region linked to $\mathrm{PD}$, metabolises relevant endogenous neural compounds, and inactivates neurotoxins known to cause Parkinsonism in animal models and humans. Many population studies have shown an increased risk of PD for CYP2D6 poor metabolizers compared with all other metabolizer types, and some PD studies that include pesticide exposures also observed $\mathrm{G} \times$ Es for poor-metabolizer variants of CYP2D6.

Incorporating individual susceptibility in risk assessment has been a challenging endeavour as there is the problem of low statistical power when testing for $\mathrm{G} \times \mathrm{E}$ in studies designed to uncover main effects of variables. There is also the problem of the complexity of measuring environmental exposures and the difficulty in assigning temporality, especially in case-control studies.

Other problems include the limited range of genetic and/or environmental variation, the redundancy of metabolic pathways, the limited scope of minor biotransformation reactions, scale dependence in the definition of statistical interaction, and a lack of biological data on the health impact of many genetic variants.

Risk management implying priority setting and sound resource allocation should rely on risk characterisation, which in turn requires deep understanding of mechanisms of action of individual risk factors and relevant dose-response relationships. Most often, however, primary prevention aimed at eliminating exposure and hence also GxE remains the most pragmatic approach and perhaps the most effective one.

\section{MIGRATION, WORK AND OCCUPATIONAL HEALTH AND SAFETY}

Alison Reid. School of Public Health, Curtin University

\subsection{6/oemed-2018-ICOHabstracts.9}

The number of people leaving their homes and crossing national borders has increased in recent decades. Today, there is an estimated 232 million migrants globally, half of whom work, and this number is anticipated to continue to increase. The migrant workforce is mixed, containing young unskilled workers, highly skilled and educated workers, and latterly females. Migrant workers from developing countries have a tendency to segment into jobs at the bottom and top of the occupational hierarchy, whereas professional migrants habitually move from one wealthy country to another. The literature is mixed about whether migrant workers experience more work -related injuries than their native-born counterparts and little is known about their exposure to carcinogens and/or other workplace hazards and whether that varies with that of their native-born counterparts. Drawing on the findings from the international literature and several studies comparing exposure to workplace hazards between migrant and native-born workers in Australia, I will address why and how migrant workers are vulnerable to adverse working conditions and how this impacts on their occupational health and safety. 